Check for updates

Cite this: RSC Adv., 2019, 9, 31115

Received 13th July 2019

Accepted 6th September 2019

DOI: 10.1039/c9ra05354a

rsc.li/rsc-advances

\section{A cobalt(II) chain based on pymca generated in situ from the hydrolysis of 2-cyanopyrimidine: spin canting and magnetic relaxation $\uparrow$}

\author{
Jie Zhang, ${ }^{a}$ Qian-Nan Zhao, ${ }^{a}$ Feng Yang, ${ }^{\mathrm{b}}$ Lei Yin, ${ }^{\mathrm{b}}$ Miao-Miao Li, ${ }^{\mathrm{a}}$ Zhenxing Wang, (DD ${ }^{\mathrm{b}}$ \\ Zhongwen Ouyang, ${ }^{\mathrm{b}}$ Zheng-Cai Xia*b and Tuo-Ping Hu (D) *a \\ A one-dimensional (1D) coordination polymer, $\left.\left[\left\{\mathrm{CO}_{2} \text { (pymca) }\right)_{2} \cdot\left(\mathrm{H}_{2} \mathrm{O}\right)_{4}\right\} \mathrm{SO}_{4} \cdot 2 \mathrm{H}_{2} \mathrm{O}\right]_{n}$ (1) (pymca $=2$ - \\ carboxypyrimidine), was solvothermally synthesized via the reaction of 2-cyanopyrimidine and $\mathrm{Co}(\mathrm{SCN})_{2}$. \\ A bidentate pymca ligand was formed in situ by the hydrolysis of 2-cyanopyrimidine. Furthermore, in this \\ study, the magnetic properties of complex 1 were investigated in detail. The results indicated that \\ complex 1 showed a single-chain magnet (SCM) behavior below ca. $3 \mathrm{~K}$. The energy barrier $\left(\Delta \tau_{1} / k_{\mathrm{B}}\right)$ and \\ preexponential factor $\left(\tau_{0}\right)$ of SCM were $31.2 \mathrm{~K}$ and $5.4 \times 10^{-9} \mathrm{~s}$, respectively.
}

\section{Introduction}

Molecule-based magnetic materials with structural diversity have a number of advantages, such as their controllable dimensions, and low energy consumption, which have attracted extensive attention. ${ }^{\mathbf{1 - 4}}$ Among them, single-chain magnets (SCMs), one type of low-dimensional molecule-based magnetic materials, have many kinds of fundamental physical properties $^{5,6}$ such as finite-sized effects and a slow relaxation behavior for the magnetization. Since the first report on SCMs in 2001, ${ }^{7}$ the molecular chain system has received considerable attention due to its potential application and value in molecular spintronic and information storage ${ }^{8-11}$ creating a new trend in the field of molecular magnetism. In the previous design and synthesis of SCMs, researchers have greatly desired to eliminate the interactions between the chains in order to obtain an isolated ferromagnetic, ferrimagnetic or spin-canted Ising chain. ${ }^{7,12}$ However, previous studies have shown that intermolecular interactions still preserve the magnetic relaxation produced by the SCM component while forming threedimensional ordering. A typical example is that by Ishida et $a{ }^{5}{ }^{5}$ and they first observed a SCM behavior below the 3D ordering temperature $\left(T_{\mathrm{C}}\right)$ in 2008 . From then until now, the magnetic relaxation of the SCM component in antiferromagnetic or metamagnetic phases was discovered in many systems, ${ }^{13-19}$ which indicated that the weak magnetic

\footnotetext{
${ }^{a}$ Department of Chemistry, College of Science, North University of China, Xueyuan Road 3, Taiyuan 030051, P. R. China.E-mail: hutuoping@nuc.edu.cn

${ }^{b}$ Wuhan National High Magnetic Field Center, School of Physics, Huazhong University of Science and Technology, Wuhan 430074, P. R. China. E-mail: xia9020@hust.edu.cn $\dagger$ Electronic supplementary information (ESI) available: TGA, bond length/angle tables. CCDC 1949664. For ESI and crystallographic data in CIF or other electronic format see DOI: 10.1039/c9ra05354a
}

interactions between the chains was perhaps not the most important prerequisite for observing the slow relaxation behavior of magnetization. Therefore, low-dimensional magnets beyond the Glauber theory ${ }^{\mathbf{2 0}}$ might result in the new development of molecule-based magnets, particularly for SCMs.

It is well-known that the $\mathrm{Co}^{\mathrm{II}}$ ion has strong Ising-like magnetic anisotropy and easily creates an energy barrier for the magnetization reversal. Therefore, it is always used as the preferred spin carrier. ${ }^{21-27}$ 2-Carboxypyrimidine (pymca) ${ }^{28}$ shows a similar coordination mode to oxalate ${ }^{29}$ and oxamide. Controlling the ratio of metal ions and ligands or changing the polarity of the solvent may reduce the number of bridging ligands around one metal ion, further leading to a onedimensional (1D) structure ${ }^{30}$ with the relaxed magnetization. Inspired by the above information, we successfully synthesized a $1 \mathrm{D}$ complex, $\left\{\left[\mathrm{Co}_{2}(\text { pymca })_{2} \cdot\left(\mathrm{H}_{2} \mathrm{O}\right)_{4}\right] \mathrm{SO}_{4} \cdot 2 \mathrm{H}_{2} \mathrm{O}\right\}_{n}$ (1), which exhibited a SCM behavior below $3 \mathrm{~K}$.

\section{Experimental}

\section{Reagents and general procedures}

All reagents and solvents were available for purchase and were used directly without further purification.

Synthesis of $\left\{\left[\mathrm{Co}_{2}(\mathrm{pymca})_{2} \cdot\left(\mathrm{H}_{2} \mathrm{O}\right)_{4}\right] \mathrm{SO}_{4} \cdot 2 \mathrm{H}_{2} \mathrm{O}\right\}_{n}(1)$

(a) A mixture of $\mathrm{Co}(\mathrm{SCN})_{2}(0.5 \mathrm{mmol}, 87.6 \mathrm{mg})$ and 2-cyanopyrimidine ( $0.5 \mathrm{mmol}, 52.6 \mathrm{mg}$ ) was dissolved in $14 \mathrm{~mL}$ of a $\mathrm{H}_{2} \mathrm{O} / \mathrm{CH}_{3} \mathrm{CN}(\mathrm{v}: \mathrm{v}=1: 1)$ mixed solution. The mixture was sealed in a $20 \mathrm{~mL}$ heavy-wall pressure resistant vessel, heated to $120^{\circ} \mathrm{C}$ for $48 \mathrm{~h}$, and then gradually cooled to $25^{\circ} \mathrm{C}$. Orange flaky crystals were collected with a yield of $56 \%$ (based on $\mathrm{Co}$ ). Elemental analysis calcd (\%) for $\mathrm{C}_{10} \mathrm{H}_{18} \mathrm{Co}_{2} \mathrm{~N}_{4} \mathrm{O}_{14} \mathrm{~S}: \mathrm{C}(21.12), \mathrm{N}$ (9.86), H (3.17), S (5.63); found: C (21.57), N (10.10), H (3.144), S 
(6.18). IR data $\left(\mathrm{cm}^{-1}\right): 3546 \mathrm{~s}, 3474 \mathrm{~s}, 3420 \mathrm{~s}, 2398 \mathrm{~m}, 2282 \mathrm{~m}$, $1626 \mathrm{~s}, 1582 \mathrm{~s}, 1474 \mathrm{~m}, 1402 \mathrm{~s}, 1296 \mathrm{w}, 1152 \mathrm{~m}, 1106 \mathrm{~m}, 1034 \mathrm{~m}$, $974 \mathrm{w}, 874 \mathrm{w}, 704 \mathrm{~m}, 676 \mathrm{~m}, 614 \mathrm{~m}$.

(b) Because $\mathrm{SO}_{4}{ }^{2-}$ ions were found in the structure of complex 1 , the synthesis of complex 1 was performed again. The reaction conditions were the same except that $\mathrm{CoSO}_{4} \cdot 7 \mathrm{H}_{2} \mathrm{O}$ (0.5 mmol, $0.1406 \mathrm{~g}$ ) was substituted for $\mathrm{Co}(\mathrm{SCN})_{2}$. Orange crystals were obtained with a yield of $60 \%$ (based on Co).

\section{X-ray crystallography}

The X-ray diffraction data for complex 1 was ascertained by selecting a suitable size for the crystals and collection using a Bruker Smart CCD area-detector diffractometer with Mo-K $\alpha$ radiation $(\lambda=0.71073 \AA)$ using a $\omega$ scan mode at $296(2) \mathrm{K}$. The crystal structure was solved by the direct method and refined by full-matrix least-squares using the SHELXTL package. All of the non-hydrogen atoms were located by the Patterson's method ${ }^{31 a}$ using the SHELXS program in the SHELXTL package and by subsequent difference Fourier syntheses. ${ }^{31 b-c}$ All the hydrogens attached to the carbon were determined theoretically and refined with isotropic thermal parameters riding on their parents. All calculations were performed by SHELXTL-2018. Crystallographic data are given in Table S1.† Bond lengths and angles for $\mathbf{1}$ were selected and are listed in Table S2.†

\section{Physical measurements}

Using the Nexus 870 FT-IR spectrometer, IR spectroscopy was performed with $\mathrm{KBr}$ particles in the range of $400-4000 \mathrm{~cm}^{-1}$. The elemental analyses of $\mathrm{C}, \mathrm{H}$, and $\mathrm{N}$ were recorded on a PerkinElmer $240 \mathrm{C}$ elemental analyzer. TGA was measured from 30 to $800{ }^{\circ} \mathrm{C}$ on a NETZSCH STA 449F3 analyzer at a heating rate of $5{ }^{\circ} \mathrm{C} \min ^{-1}$ under a $\mathrm{N}_{2}$ atmosphere. The ac magnetic susceptibility data were collected using a MPMS-XL7 Squid magnetometer (test conditions: $H_{\mathrm{ac}}=5 \mathrm{Oe}, H_{\mathrm{dc}}=0$ Oe, frequencies ranging from 1 to $1488 \mathrm{~Hz}$ ). The dc magnetic susceptibility data were measured in the temperature range of $1.8-300 \mathrm{~K}$. The experimental susceptibilities were corrected for the diamagnetism of the samples as estimated from Pascal's tables ${ }^{31 d}$ and the sample holder by a previous calibration. Pulsed-high-field magnetization measurements were performed at $1.9 \mathrm{~K}$ using a home-made pulsed field up to $30 \mathrm{~T}$ at the Wuhan National High Magnetic Field Center, P. R. China. The sweeping rate for the magnetic field was $5.0 \mathrm{kT} \mathrm{s}^{-1}$ on an average. The low-field magnetization data (on SQUID) were used to calibrate the high-field magnetization curve, which is a standard way to process the high field magnetization data. ${ }^{31 e}$

\section{Results and discussion}

\section{Synthesis}

The reaction for the hydrolysis of nitriles to carboxylic acids and ammonia is very common. The reaction temperature as well as the acidity and alkalinity of the solution will greatly affect the reaction rate. ${ }^{28}$ The mechanism for pymca generated from 2cyanopyrimidine in situ is described in Scheme 1. Briefly, 2cyanopyrimidine was hydrolyzed at a high temperature to form

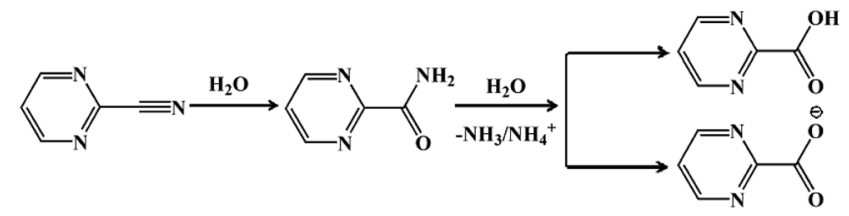

Scheme 1 The hydrolysis process for 2-cyanopyrimidine to pymca.

2-amidopyrimidine, which lost ammonia or the ammonium ion under weakly basic conditions, finally forming 2-carboxypyrimidine or the 2-carboxypyrimidine ion. Moreover, a detailed discussion on the ligand pymca in situ synthesis by the hydrothermal reaction was described by Colacio et al. ${ }^{28}$ They believed pymca, a proposed intermediate between bipyrimidine and oxalate, was generated in situ from the hydrolysis of 2-cyanopyrimidine. Herein, we only briefly mention the slight difference between the methods from the reference and ours. In Colacio's work, a two-dimensional (2D) structure with a spincanted antiferromagnet that led to a weak ferromagnetism was synthesized by the reaction of the metal ions and pymca ligands (molar ratio of $1: 1$ ) in a water solution at $190{ }^{\circ} \mathrm{C}$.

To obtain the 1D structure, a more effective method was used to reduce the coordination ability of the pymca ligand by changing the polarity of the reaction solvent. Therefore, in this study, $\mathrm{CH}_{3} \mathrm{CN}$, whose polarity is weaker than that of water, was used as one of the solvents. The title complex 1 was obtained by the reaction of $\mathrm{Co}(\mathrm{SCN})_{2}$, 2-cyanopyrimidine and $\mathrm{H}_{2} \mathrm{O} / \mathrm{CH}_{3} \mathrm{CN}$ mixed solution. However, the results showed that a sulfate ion appeared in the structure instead of a thiocyanate ion. This phenomenon was attributed to the oxidation of the $\mathrm{SCN}^{-}$ion to a $\mathrm{SO}_{4}{ }^{2-}$ ion (Scheme 2). ${ }^{32}$

Therefore, in order to examine the effects of different charge balancing ions (anions), the synthesis of complex 1 was performed again. The reaction conditions were the same as those mentioned above, except that $\mathrm{Co}(\mathrm{SCN})_{2}$ was replaced by $\mathrm{CoSO}_{4} \cdot 7 \mathrm{H}_{2} \mathrm{O}, \mathrm{CoCl}_{2}$, and $\mathrm{Co}\left(\mathrm{ClO}_{4}\right)_{2}, \mathrm{Co}\left(\mathrm{NO}_{3}\right)_{2}$, respectively. However, the crystals of complex 1 were obtained only in the $\mathrm{CoSO}_{4}$ solution, implying that the presence of the $\mathrm{Cl}^{-}, \mathrm{ClO}_{4}{ }^{-}$, $\mathrm{NO}_{3}{ }^{-}$ions could not produce the title complex. The different anions herein mainly regulated the $\mathrm{pH}$ of the reaction system. Another unexpected result was that the pymca directly used as the reactant could not obtain 1 under the same conditions. We speculated that complex 1 needed to be crystallized in a weak alkaline environment due to the production of amino groups during the in situ hydrolysis reaction of $\mathrm{CN}^{-}$to $\mathrm{COO}^{-}$. When only pymca ligands were added, the reaction system was a weak acidic condition. Therefore, the ligand was hard to remove the proton and was not suitable for crystal crystallization. The above results also showed that the synthesis reaction of complex 1 depended on many factors.

$$
\mathrm{SCN}^{-}+\mathrm{H}^{+}+5 \mathrm{O}_{2} \longrightarrow \mathrm{SO}_{4}{ }^{2-}+\mathrm{HCO}_{3}^{-}+\mathrm{NO}_{3}^{-}
$$

Scheme 2 The oxidation process for thiocyanate to the sulfate ion. 


\section{XRD and thermal analyses}

The X-ray powder diffraction analysis was performed at room temperature to check the phase purity of complex 1. As shown in Fig. $\mathrm{S} 1, \uparrow$ the experimental PXRD patterns were in agreement with the simulated patterns, demonstrating the good phase purity of $\mathbf{1}$. To further verify the thermal stability of complex $\mathbf{1}$, a thermogravimetric curve was generated (Fig. S2 $\dagger$ ). The weight loss of $6.5 \%$ was due to the loss of two lattice water molecules from $60{ }^{\circ} \mathrm{C}$ to $100{ }^{\circ} \mathrm{C}$ (calcd: $6.4 \%$ ). After $120{ }^{\circ} \mathrm{C}$, the weight loss of $12.5 \%$ corresponded to the loss of four coordinated water molecules (calcd: 12.7\%). The framework started to decompose above $350^{\circ} \mathrm{C}$, finally generating the thermally stable powder. In addition, the XRD analysis showed that the crystallinity of 1 still remained at $350{ }^{\circ} \mathrm{C}$ (Fig. $\mathrm{S} 3 \dagger$ ).

\section{Descriptions of crystal structures}

The single-crystal X-ray diffraction analysis showed that complex 1 crystallized in the tetragonal system with a $P \overline{4} 2_{1} c$ space group. The asymmetric unit of 1 contained two $\mathrm{Co}^{\mathrm{II}}$ ions, two pymca ligands, four coordination water molecules (O1W, $\mathrm{O}_{1} \mathrm{~W}^{\mathrm{v}}$, and $\mathrm{O} 2 \mathrm{~W}, \mathrm{O} 2 \mathrm{~W}^{\mathrm{iii}}$ ), one lattice sulfate ion, and two lattice water molecules (Fig. 1a with symmetry codes). The Co1 and Co2 ions had the same coordination environment. The Co1 ion was coordinated by the $\mathrm{N} 1$ and $\mathrm{O} 1$ atoms from the same pymca ligand, $\mathrm{N} 1^{\mathrm{v}}$ and $\mathrm{O}^{\mathrm{v}}$ of another pymca ligand $(\mathrm{Co} 1-\mathrm{O} 1=$ 2.107(1) and Co1-N1 = 2.157(8) $\AA$ ), and two O atoms (O1W, $\mathrm{O}_{1} \mathrm{~W}^{v}$ ) from two coordinated water molecules, presenting a distorted octahedral geometry. $\mathrm{Co} 2$ was centrosymmetric and surrounded by two $\mathrm{O}$ atoms $\left(\mathrm{O} 2 \mathrm{~W}, \mathrm{O} 2 \mathrm{~W}^{\mathrm{iii}}\right)$ from two coordinated water molecules, two carboxylate $\mathrm{O}$ atoms $\left(\mathrm{O} 2, \mathrm{O} 2^{\mathrm{iii}}\right)$, and two $\mathrm{N}$ atoms $\left(\mathrm{N} 2, \mathrm{~N} 2{ }^{\mathrm{iii}}\right)$ from two different pymca ligands.

Although the coordination environments of Co1 and Co2 were the same, the shapes of the distorted octahedrons were different $\left(\mathrm{N} 1-\mathrm{Co} 1-\mathrm{N} 1^{\mathrm{v}}=99.3(3)^{\circ}, \mathrm{N} 2-\mathrm{Co} 2-\mathrm{N} 2^{\mathrm{iii}}=164.9(3)^{\circ}\right)$ (Fig. $\mathrm{S} 4 \dagger$ ), which meant that the neighboring two pymca ligands were not coplanar and almost vertical to each other. Their

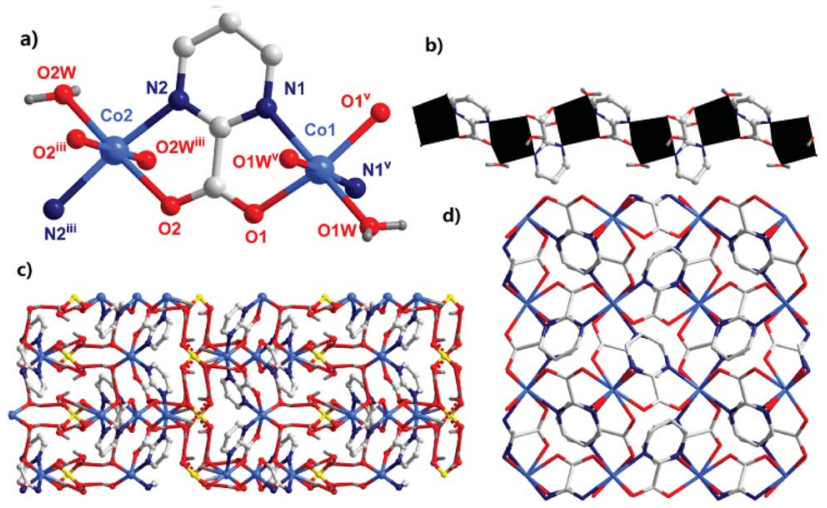

Fig. 1 (a) The bonding environment of the Co"l ions (symmetry codes: (i) $-x+1,-y, z$; (ii) $-x+1,-y+1, z$; w: water molecules). (b) The $1 \mathrm{D}$ chain was formed by dinuclear units via a regular alternating pattern. (c) The hydrogen bonding between the adjacent 1D chains (hydrogen bonds are represented by dashed lines). (d) The perpendicular 1D chains extend along the $a$ and $b$ directions and form a tetragonal grid. dihedral angles were $83.577^{\circ}$ and $80.473^{\circ}$ around Co1 and Co2, respectively. For $\mathbf{1}$, the oxygen and nitrogen atoms of the pymca ligands adopted chelated and bridged modes to connect the $\mathrm{Co}^{\mathrm{II}}$ ions, forming a 1D zigzag chain (Fig. 1b), which was further packed into a 3D supramolecular structure by hydrogen bonding interactions between adjacent chains, lattice water molecules, and sulfate ions (Fig. 1c and Table S3†). The adjacent chains were perpendicular to each other and extended along $a$ and $b$ directions to form the final 3D supramolecular framework (Fig. 1d). The shortest Co $\cdots$ Co intrachain and interchain separations were $5.591 \AA$ and $5.298 \AA$, respectively.

\section{DC magnetic measurements}

The variable temperature magnetic susceptibility of $\mathbf{1}$ was measured on an applied field of 2 kOe at 1.8-300 K. The $\chi_{M} T$ value of $2.64 \mathrm{~cm}^{3} \mathrm{~mol}^{-1} \mathrm{~K}$ was larger than the theoretical value of one isolated high spin $\mathrm{Co}^{\mathrm{II}}$ ion $\left(1.875 \mathrm{~cm}^{3} \mathrm{~mol}^{-1} \mathrm{~K}\right.$ with $g=2$ and $S=3 / 2$ ) at an ambient temperature (Fig. 2), indicating the existence of the orbital contribution of $\mathrm{Co}^{\mathrm{II}}$ in the octahedral coordination ligand field. ${ }^{33}$ As the temperature decreased, the $\chi_{\mathrm{M}} T$ value steadily declined until $16 \mathrm{~K}$ and reached a minimum value of $0.95 \mathrm{~cm}^{3} \mathrm{~mol}^{-1} \mathrm{~K}$, which arose from the spin-orbit coupling effects or the antiferromagnetic interactions between the $\mathrm{Co}^{\mathrm{II}}$ ions. $^{28}$ Then, the $\chi_{\mathrm{M}} T$ value rapidly increased to a maximum of $3.65 \mathrm{~cm}^{3} \mathrm{~mol}^{-1} \mathrm{~K}$ at $5 \mathrm{~K}$ and sharply decreased to $3.16 \mathrm{~cm}^{3} \mathrm{~mol}^{-1} \mathrm{~K}$ at $1.8 \mathrm{~K}$. For one non-interacting $\mathrm{Co}^{\mathrm{II}}$ ion, the limit value was $1.7 \mathrm{~cm}^{3} \mathrm{~mol}^{-1} \mathrm{~K}$ (ref. 34) as obtained from

$$
\chi_{\mathrm{M}} T_{T \rightarrow 0}=\frac{N \mu_{\mathrm{B}}^{2} g_{0}^{2}}{3 k} S(S+1) \cong \frac{3 g_{0}^{2}}{32} \approx 1.7
$$

the minimum $\chi_{\mathrm{M}} T$ value of complex 1 was $0.95 \mathrm{~cm}^{3} \mathrm{~mol}^{-1} \mathrm{~K}$ that was lower than the limit value. Therefore, the coupling between the $\mathrm{Co}^{\mathrm{II}}$ ions was antiferromagnetic. However, in the whole temperature range, $\chi_{\mathrm{M}} T-T$ showed a ferrimagnet-like plot instead of an antiferromagnetic curve, which implied that the canted spins possibly dominated the magnetic properties ${ }^{35 a}$ because the two $\mathrm{Co}^{\mathrm{II}}$ ions in the asymmetrical unit and the net spins led to a saturated $\chi_{M}$ value along the external field of 2

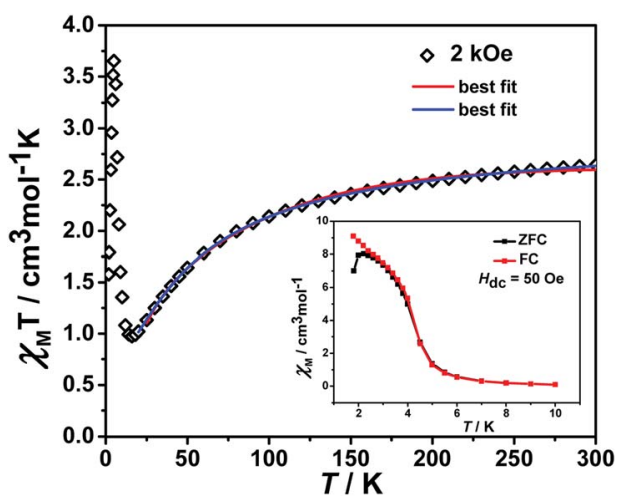

Fig. 2 The plot of $\chi_{M} T$ vs. T. The data was measured under a $2 \mathrm{kOe} d \mathrm{c}$ field. The red line is fitted using a modified empirical expression and the blue line is fitted by the phenomenological method. Insert: plot of ZFC-FC under a DC field of 50 Oe. 
kOe. This phenomenon prompted us to further explore the SCM behavior. The field-cooling (FC) and zero-field-cooling (ZFC) were tested under a 50 Oe DC field in "Temperature Stable" mode from $1.8 \mathrm{~K}$ to $10 \mathrm{~K}$. The ZFC and FC curves diverged at $c a$. $3 \mathrm{~K}$ (Fig. 2 inset), which was considered as the blocking temperature of the chain complex. From the ZFC-FC curve, the Co chain had weak ferromagnetic ordering at low temperatures. No proper models could fit the variable-temperature magnetic data in the whole temperature region. To further quantitatively interpret the behavior, a modified empirical expression ${ }^{34}$ for octahedral high-spin $\mathrm{Co}^{\mathrm{II}}$ was employed in the temperature range of $24-300 \mathrm{~K}$ by replacing the $g$ factor with the $G(T, J)$ function, taking into account the spin-orbital coupling and exchange coupling.

$$
\chi_{M}=\frac{N \beta^{2}[G(T, J)]^{2}}{k T}\left\{\frac{0.25+0.14995 x+0.30094 x^{2}}{1+1.9826 x+0.68854 x^{2}+6.0626 x^{3}}\right\}
$$

With

$$
x=\left(\frac{25}{18}\right)|J| / k T
$$

Using this model, the best-fit (red line) parameters were obtained: $J=-6.0(3) \mathrm{cm}^{-1}, \alpha=1.18(3), \Delta=-792(27) \mathrm{cm}^{-1}$, and $\lambda$ $=-170 \mathrm{~cm}^{-1}$ (fixed). The negative $J$ value indicated the antiferromagnetic coupling between the $\mathrm{Co}^{\mathrm{II}}$ ions within the chain.

In order to further obtain the interchain interactions, the variable-temperature magnetic data was fitted by the phenomenological method (blue line) reported by Rueff et al. ${ }^{35 b, 35 c}$ with the equation taking the mean-field correction into account as the following:

$$
\begin{gathered}
\chi T=A \exp \left(-E_{1} / k T\right)+B \exp \left(-E_{2} / k T\right) \\
J=-2 E_{2} / k \\
\chi_{\mathrm{M}}=\frac{\chi}{1-\left(\frac{2 z j^{\prime}}{N g^{2} \beta^{2}}\right) \chi}
\end{gathered}
$$

giving the Curie constant, $C=A+B=5.90 \mathrm{~cm}^{3} \mathrm{~mol}^{-1} \mathrm{~K}$, which was consistent with six-coordinated high-spin $\mathrm{Co}^{\mathrm{II}}$ ions. The spin-orbit coupling constant was $-E_{1} / k=-50.51 \mathrm{~K}$. The spinspin coupling constant was $-E_{2} / k=-2.11 \mathrm{~K}, J=-4.22 \mathrm{~K}$ (or $6.08 \mathrm{~cm}^{-1}$ ) and the interchain interaction was $z j^{\prime}=0.01 \mathrm{~K} \mathrm{using}$ the mean-field theory correction. After comparing the two fitting results, it was found that the values of the intra-chain coupling were the same, which proved the correctness of the fitting method.

The magnetization hysteresis loops were measured and are shown in Fig. 3 with two obvious regions at $1.8 \mathrm{~K}$. In the low DC fields below $2.89 \mathrm{kOe}$, the magnetization sharply increased to $0.37 N \mu_{\mathrm{B}}$. Above this field, the magnetization slowly increased linearly to a maximum of $0.60 N \mu_{\mathrm{B}}$ in $7 \mathrm{~T}$. For the octahedral high-spin $\mathrm{Co}^{\mathrm{II}}$ at low temperatures, an effective spin with $S=1$ / 2 and $g_{\text {av }}=4.4$ was assumed for the low-lying doublet. Therefore, the saturated value for one isolated $\mathrm{Co}^{\mathrm{II}}$ ion was $2.2 N \mu_{\mathrm{B}}$.

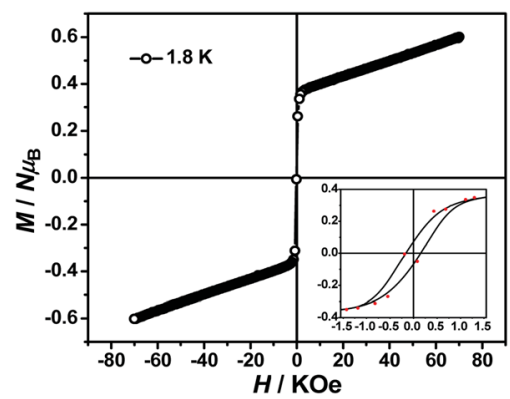

Fig. 3 Magnetic hysteresis loops obtained at $1.8 \mathrm{~K}$.

The small experimental value $\left(0.60 N \mu_{\mathrm{B}}\right)$ suggested a strong antiferromagnetic coupling interaction with spin canting in 1. To determine the spin canting, the high-field magnetization was measured. The $M(H)$ curve was obtained by calibrating to the SQUID data at $1.9 \mathrm{~K}$ (Fig. 4), which illustrated the main role of the antiferromagnetic coupling. Due to the quick sweeping rate of the magnetic field $\left(5.0 \mathrm{kT} \mathrm{s}^{-1}\right.$ on an average), virgin magnetization was observed during the increase in the field process. In the decreasing process, the low-field magnetization coincided well with the results measured in SQUID. The virgin and normal magnetizations, which led to a loop, were easily observed in the magnets with an antiferromagnetic coupling such as metamagnets. ${ }^{36 a}$ In the low field, the spins for complex 1 were easily magnetized and quickly reached a platform area, which was ascribed to the saturation state of the spins in the domain. The $M$ value in the platform was much lower than $2.2 N \mu_{\mathrm{B}}$ for one $\mathrm{Co}^{\mathrm{II}}$ ion. Therefore, complex 1 was a weak ferromagnetic chain based on spin canting. Upon increasing the field, an S-shape curve was observed, which was a result of the antiferromagnetic coupling between the spins quenched by the field. Field decoupling led to all the spins gradually arranging along the direction of an external field. At $30 \mathrm{~T}$, the $M=1.99$ $N \mu_{\mathrm{B}}$ approached a saturation value of $2.2 N \mu_{\mathrm{B}}$, which was calculated based on one $\mathrm{Co}^{\mathrm{II}}$ ion. These results obviously indicated the spin canting in complex 1 . When the linear part of $M-H$ (Fig. 3) in the high field was extended, the intersection point with a longitudinal axis was $0.364 N \mu_{\mathrm{B}}$, which was roughly regarded as the fully magnetized canting spins in the chain. Therefore, the canting angle was estimated as $9.5^{\circ}(\sin \theta=0.364 / 2.2)$.

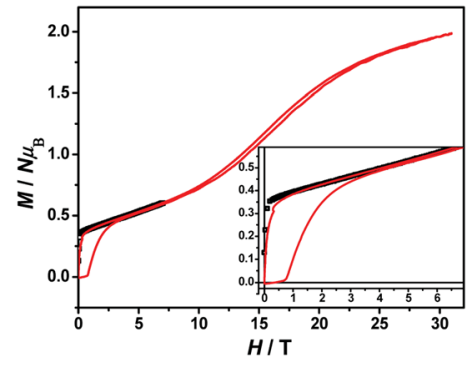

Fig. 4 The $M-H$ curve of 1 measured in a high field at $1.9 \mathrm{~K}$. 


\section{AC magnetic measurements}

To further investigate the SCM properties and magnetic relaxation mechanism of complex $\mathbf{1}$, the fully ground $\mathbf{1}$ was subjected to alternating current (ac) magnetic measurements from $1 \mathrm{~Hz}$ to $1488 \mathrm{~Hz}$ at lower temperatures of $1.8 \mathrm{~K}-5.0 \mathrm{~K}$. There were two obvious frequency-dependent peaks for both, the in-phase $\left(\chi_{\mathrm{M}}^{\prime}\right)$ and out-of-phase $\left(\chi_{M}^{\prime \prime}\right)$ AC susceptibility (Fig. 5 and S5 $\dagger$ ). Below $3.2 \mathrm{~K}$, the maximum value for $\chi_{\mathrm{M}}^{\prime \prime}$ moved to a higher temperature as the frequency increased for the $\chi_{M}^{\prime \prime}-T$ curves. The Mydosh parameter $(\varphi)$ was estimated to be 0.29 ( $\varphi$ is used to measure the frequency dependence, $\varphi=\left(\Delta T_{\mathrm{p}} / T_{\mathrm{p}}\right) / \Delta(\log f){ }^{36 \boldsymbol{b}} T_{\mathrm{p}}$ denotes the temperature for the maximum in the $\chi^{\prime \prime}-T$ curves, and $f$ is the AC frequency), which was in the range of 0.1-0.3 as expected for the superparamagnetic behavior in SCMs. Conversely, $\varphi$ was calculated to be 0.07 for the high-temperature region of 3.4-5.0 K, corresponding to spin glass characteristics $(0.01<\varphi<0.08) .^{36 c, 36 d, 37}$ A Cole-Cole curve was significantly semicircular and distributed only at 1.8-3.2 K (Fig. S6a $\dagger$ ). In the graph we clearly observed a slow relaxation process in this temperature range. The Arrhenius plots of the relaxation times $(\tau)$ were obtained from the temperature-dependent $\chi_{M}^{\prime \prime}$ peaks because the peaks could only be clearly separated in Fig. 5 in two temperature regions. According to the Arrhenius law, $\tau=$ $\tau_{0} \exp \left(\Delta \tau / k_{\mathrm{B}} T\right)$, the anisotropy barrier $\left(\Delta \tau / k_{\mathrm{B}}\right)$ and the preexponential factor $\left(\tau_{0}\right)$ were extracted, giving a value of $\Delta \tau / k_{\mathrm{B}}$ $=31.2 \mathrm{~K}$, which was close to that in previously reported literature. ${ }^{38-40}$ The values of $\tau_{0}=5.4 \times 10^{-9} \mathrm{~s}(2.0-3.2 \mathrm{~K})$ and $152.4 \mathrm{~K}$, $1.5 \times 10^{-20} \mathrm{~S}(3.4-5.0 \mathrm{~K})$, respectively (Fig. S6†) exceeded that in literature. ${ }^{\mathbf{4 1 , 4 2}}$ The long spin reversal time fell within a range for low-dimensional magnets (SCM), while the short spin was suggested from the spin glasses. The data obtained at high temperatures was fitted using the conventional critical scaling law for spin dynamics (Fig. $\mathbf{S} 7 \dagger$ ). According to the equation, $\tau=$ $\tau_{\mathrm{o}}\left[\left(T_{\mathrm{p}}-T_{\mathrm{f}}\right) / T_{\mathrm{f}}\right]-z \nu$, the parameters were $\tau_{0}=1.32 \times 10^{-4} \mathrm{~s}, z \nu=$ 12 , and $T_{\mathrm{f}}=2.2 \mathrm{~K}$. The $z \nu$ value fell in the region for all kinds of spin glasses (4-12), and the frozen temperature was $2.2 \mathrm{~K} .^{37,43,44}$ The high-temperature signal observed in the out-of-phase indicated the formation of magnetic domains due to the interchain ferromagnetic interactions with a short distance between chains. The examples of weak ferromagnetic intermolecular interactions that lead to $3 \mathrm{D}$ magnetic properties are very rare because the antiferromagnetic intermolecular interactions always make the system more stable. ${ }^{43}$
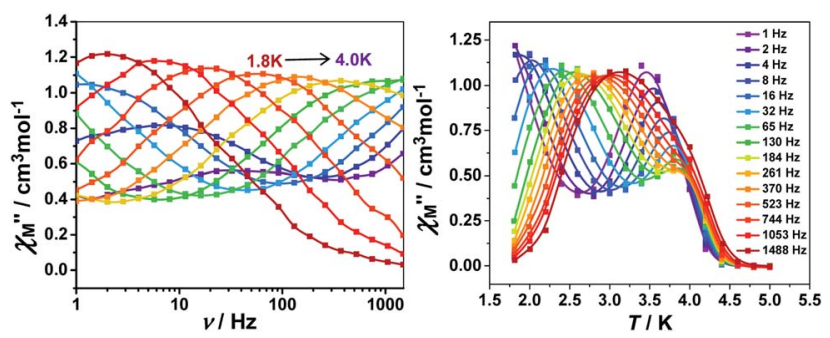

Fig. 5 Frequency dependence of the out-of-phase (left) and temperature dependence for the out-of-phase (right) components for the AC susceptibility in 1 with a zero applied static field and an oscillating field of $5 \mathrm{Oe}$ at a frequency region of $1-1488 \mathrm{~Hz}$.
The variable-temperature magnetic susceptibility $\left(\chi_{M} T\right)$ was proportional to the correlation length $(\xi)$ in any $1 \mathrm{D}$ typical system under a DC field of 0 Oe. For an Ising-like or anisotropic Heisenberg $1 \mathrm{D}$ system, as the temperature decreases, $\chi_{\mathrm{M}} T$ increases exponentially, which can be expressed by the following equation: $\chi_{\mathrm{M}} T \approx C_{\text {eff }} \times \exp \left(\Delta_{\xi} / k_{\mathrm{B}} T\right)$. The parameters in the expression, $C_{\text {eff }}$ and $\Delta_{\xi}$, denote the effective Curie constant and the correlation energy used to create a domain wall along the chain, respectively. ${ }^{10,45-47}$ According to the above equation, as shown in Fig. 6, the plot of $\ln \left(\chi_{\mathrm{M}}^{\prime} T\right)$ versus $1 / T$ is a straight line, which is consistent with the above-mentioned model, whose slope is equal to the correlation at $4-5 \mathrm{~K}$ and yielded a $\Delta_{\xi} / k_{\mathrm{B}}=25.36 \mathrm{~K}$ and $C_{\text {eff }}=0.056$ $\mathrm{cm}^{3} \mathrm{~mol}^{-1} \mathrm{~K}$. The decrease in the $\ln \left(\chi_{\mathrm{M}}^{\prime} T\right)$ value indicated that the correlation length was larger than the average separation between the two intrinsic defects along the chain. We noticed a broad shoulder bulge in Fig. 6, implying that the interchain interaction demonstrated some influence compared to the anisotropy of the chain. ${ }^{48}$ For 1D systems falling within the Ising limit, when the spin was canted along the chain, the activation energy $\left(\Delta_{\xi}\right)$ was calculated by the expression $\Delta_{\xi}=4|J| S^{2} \cos \theta\left(\mathrm{Co}^{\mathrm{II}}\right.$ at low temperatures was an $S=1 / 2$ effective spin). The calculated value was $8.52 \mathrm{~K}$, which was much less than the value fitted by the plot of $\ln \left(\chi_{M}^{\prime} T\right)$ versus $1 / T$. This result showed that in this chain system, the relationship between $\Delta_{\xi}$ and the magnetic parameters $(S, J)$ was uncertain. $^{45 b}$

From the Glauber dynamics, the energy barrier for the spin reversal should be $\Delta \tau=\Delta_{\xi}$ for finite-sized Ising chains and $\Delta \tau=$ $2 \Delta_{\xi}$ for infinite Ising chains,,$^{\mathbf{9 , 1 1}, \mathbf{4 9}}$ wherein naturally occurring defects limit the growth of the correlation length. However, the anisotropic Heisenberg model is more common in elaborating the spin reversal energy barrier of SCMs because the anisotropy energy of each magnetic unit was considered in the model. ${ }^{20}$ The correlation length $(\xi)$ increased exponentially when the temperature decreased. The overall energy barrier $(\Delta \tau)$ was $\Delta \tau=$ $2 \Delta_{\xi}+\Delta_{\mathrm{A}}$ for an infinite chain at high temperatures and $\Delta \tau=\Delta_{\xi}$ $+\Delta_{\mathrm{A}}$ for a finite-sized chain at low temperatures, where $\Delta_{\mathrm{A}}$ denotes the intrinsic anisotropic barrier for the individual spin without a magnetic exchange. ${ }^{45}$ According to the fitting above (Fig. S6b $\dagger$ ), the low-temperature energy barrier (2.0-3.2 K) was $\Delta \tau / k_{\mathrm{B}}=31.2 \mathrm{~K}$, which was obviously larger than $\Delta_{\xi} / k_{\mathrm{B}}$. Therefore, the intrinsic anisotropic barrier $\left(\Delta_{\mathrm{A}}\right)$ for the finite-sized chain was estimated using $\Delta_{\mathrm{A}}=\Delta \tau / k_{\mathrm{B}}-\Delta_{\xi} / k_{\mathrm{B}}$ to be $5.84 \mathrm{~K}$.

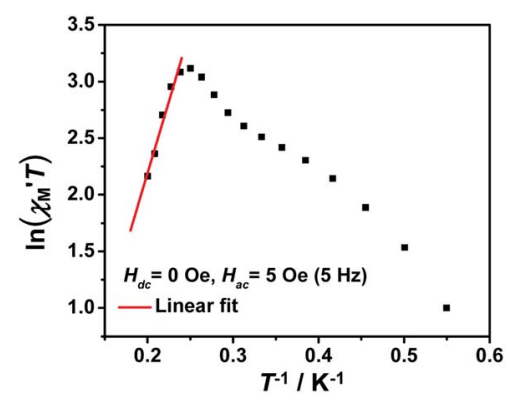

Fig. 6 The $\ln \left(\chi_{M}^{\prime} T\right)$ vs. $1 / T$ curve of 1 collected in a DC field of 0 Oe on an oscillating field of $5 \mathrm{Oe}$ at $5 \mathrm{~Hz}$. The solid red line represents the fit of the linear part of the data. 


\section{Conclusions}

In summary, a novel chain was solvothermally synthesized by the reaction of $\mathrm{Co}(\mathrm{SCN})_{2}$ and 2-cyanopyrimidine. The DC magnetic data in $2 \mathrm{kOe}$ and the magnetization in the range of 0 to $30 \mathrm{~T}$ showed that the ligand mediated the antiferromagnetic coupling between the intrachain $\mathrm{Co}^{\mathrm{II}}$ ions, leading to a spin-canting order. The AC magnetic measurements and analysis results demonstrated that of spin glass at high temperatures. As the temperature decreased, the title complex showed a slow relaxation in the magnetization, resulting from the SCM component with an energy barrier of $\Delta \tau_{1} / k_{\mathrm{B}}=31.2 \mathrm{~K}$ and preexponential factor of $\tau_{0}=5.4 \times 10^{-9} \mathrm{~s}$. The blocking temperature was $c a .3 \mathrm{~K}$. The information in this study provides an example for designing new types of SCMs obtained by the hydrolysis of 2-cyanopyrimidine in situ.

\section{Conflicts of interest}

There are no conflicts to declare.

\section{Acknowledgements}

The authors gratefully acknowledge the financial support of this work by the NSF of China (Grant 21676258), the International Scientific and Technological Cooperation Projects of Shanxi Province (No: 201803D421080), and the Central Leading Local Science and Technology Development Special Fund Project (YDZX20191400002636). The authors are also grateful for the support from the Innovative Research Team of InorganicOrganic Hybrid Functional Materials at North University of China.

\section{Notes and references}

1 D. Gatteschi, R. Sessoli and J. Villain, Molecular nanomagnets, Oxford University Press, 2006.

2 M. Chen, H. Zhao, E. C. Sañudo, C.-S. Liu and M. Du, Inorg. Chem., 2016, 55, 3715.

3 M. R. Saber and K. R. Dunbar, Chem. Commun., 2014, 50, 12266.

4 Y.-Z. Zheng, Z. Zheng and X.-M. Chen, Coord. Chem. Rev., 2014, 1, 258.

5 N. Ishii, Y. Okamura, S. Chiba, T. Nogami and T. Ishida, J. Am. Chem. Soc., 2008, 130, 24.

6 T. Kajiwara, H. Tanaka, M. Nakano, S. Takaishi, Y. Nakazawa and M. Yamashita, Inorg. Chem., 2010, 49, 8358.

7 A. Caneschi, D. Gatteschi, N. Lalioti, C. Sangregorio, R. Sessoli, G. Venturi, A. Vindigni, A. Rettori, M. G. Pini and M. Novak, Angew. Chem., Int. Ed., 2001, 40, 1760.

8 T.-T. Wang, M. Ren, S.-S. Bao, B. Liu, L. Pi, Z.-S. Cai, Z.-H. Zheng, Z.-L. Xu and L.-M. Zheng, Inorg. Chem., 2014, 53, 3117.

9 L. Bogani, A. Vindigni, R. Sessoli and D. Gatteschi, J. Mater. Chem., 2008, 18, 4750.

10 T. D. Harris, M. V. Bennett, R. Clérac and J. R. Long, J. Am. Chem. Soc., 2010, 132, 3980.
11 H. Miyasaka, M. Julve, M. Yamashita and R. Clérac, Inorg. Chem., 2009, 48, 3420.

12 R. J. Glauber, J. Math. Phys., 1963, 4, 294.

13 C. Coulon, R. Clérac, W. Wernsdorfer, T. Colin and H. Miyasaka, Phys. Rev. Lett., 2009, 102, 167204.

14 Y.-Z. Zheng, W. Xue, M.-L. Tong, X.-M. Chen, F. Grandjean and G. J. Long, Inorg. Chem., 2008, 47, 4077.

15 X.-M. Zhang, Y.-Q. Wang, K. Wang, E.-Q. Gao and C.-M. Liu, Chem. Commun., 2011, 47, 1815.

16 L. M. Toma, F. S. Delgado, C. Ruiz-Perez, R. Carrasco, J. Cano, F. Lloret and M. Julve, Dalton Trans., 2004, 2836.

17 S. Wöhlert, J. Boeckmann, M. Wriedt and C. Näther, Angew. Chem., Int. Ed., 2011, 50, 6920.

18 L. M. Toma, C. Ruiz-Pérez, J. Pasán, W. Wernsdorfer, F. Lloret and M. Julve, J. Am. Chem. Soc., 2012, 134, 15265.

19 (a) J. H. Yoon, D. W. Ryu, H. C. Kim, S. W. Yoon, B. J. Sun and C. S. Hong, Chem.-Eur. J., 2009, 15, 3661; (b) J.-B. Peng, Q.-C. Zhang, X.-J. Kong, Y.-Z. Zheng, Y.-P. Ren, L.-S. Long, R.-B. Huang, L.-S. Zheng and Z.-P. Zheng, J. Am. Chem. Soc., 2012, 134, 3314.

20 W.-X. Zhang, R. Ishikawa, B. Breedlove and M. Yamashita, RSC Adv., 2013, 3, 3772.

21 M. Murrie, S. J. Teat, H. Stœckli-Evans and H. U. Güdel, Angew. Chem., Int. Ed., 2003, 42, 4653.

22 T.-F. Liu, D. Fu, S. Gao, Y.-Z. Zhang, H.-L. Sun, G. Su and Y.-J. Liu, J. Am. Chem. Soc., 2003, 125, 13976.

23 A. V. Palii, O. S. Reu, S. M. Ostrovsky, S. I. Klokishner, B. S. Tsukerblat, Z.-M. Sun, J.-G. Mao, A. V. Prosvirin, H.-H. Zhao and K. R. Dunbar, J. Am. Chem. Soc., 2008, 130, 14729.

24 Y.-Q. Wang, W.-W. Sun, Z.-D. Wang, Q.-X. Jia, E.-Q. Gao and Y. Song, Chem. Commun., 2011, 47, 6386.

25 N. Ishii, T. Ishida and T. Nogami, Inorg. Chem., 2006, 45, 3837.

26 M. Rams, M. Böhme, V. Kataev, Y. Krupskaya, B. Büchner, W. Plass, T. Neumann, Z. Tomkowicz and C. Näther, Phys. Chem. Chem. Phys., 2017, 19, 24534.

27 (a) Y.-Z. Zhang, B. S. Dolinar, S. Liu, A. J. Brown, X. Zhang, Z.-X. Wang and K. R. Dunbar, Chem. Sci., 2018, 9, 119; (b) M.-M. Wang, X.-S. Gou, W. Shi and P. Cheng, Chem. Commun. 2019, 55, 11000.

28 A. Rodríguez-Diéguez, J. Cano, R. Kivekäs, A. Debdoubi and E. Colacio, Inorg. Chem., 2007, 46, 2503.

29 R. Clément, S. Decurtins, M. Gruselle and C. Train, Monatsh. Chem., 2003, 134, 117.

30 O. Kahn, Y. Pei, M. Verdaguer, J. P. Renard and J. Sletten, J. Am. Chem. Soc., 1988, 110, 782.

31 (a) A. L. Patterson, Phys. Rev., 1934, 46, 372; (b) G. Sheldrick, Acta Crystallogr., Sect. A: Found. Crystallogr., 2008, 64, 112; (c) G. Sheldrick, Acta Crystallogr., Sect. C: Struct. Chem., 2015, 71, 3; (d) G. A. Bain and J. F. Berry, J. Chem. Educ., 2008, 85, 532; (e) X.-Y. Yue, Z.-W. Ouyang, M.-Y. Cui, L. Yin, G.-L. Xiao, Z.-X. Wang, J. Liu, J.-F. Wang, Z.-C. Xia, X.-Y. Huang and Z.-Z. He, Inorg. Chem., 2018, 57, 3151.

32 C. Sun, C. Zhang, A. Li, C. Jiang, X. Wang and M. Huo, Catal. Commun., 2011, 12, 384.

33 M. Murrie, Chem. Soc. Rev., 2010, 39, 1986. 
34 (a) J.-Y. Zhang, J.-X. Shi, L.-Y. Chen, Q.-X. Jia, W. Deng and E.-Q. Gao, CrystEngComm, 2017, 19, 1738; (b) F. Lloret, M. Julve, J. Cano, R. Ruiz-García and E. Pardo, Inorg. Chim. Acta, 2008, 361, 3432.

35 (a) J.-P. Zhao, Q. Yang, Z.-Y. Liu, R. Zhao, B.-W. Hu, M. Du, Z. Chang and X.-H. Bu, Chem. Commun., 2012, 48, 6568; (b) J. Rueff, N. Masciocchi, P. Rabu, A. Sironi and A. Skoulios, Eur. J. Inorg. Chem., 2001, 11, 2843; (c) J. Rueff, N. Masciocchi, P. Rabu, A. Sironi and A. Skoulios, Chem.Eur. J., 2002, 8, 1813.

36 (a) H. Kumagai, C. J. Kepert and M. Kurmoo, Inorg. Chem., 2002, 41, 3410; (b) V. Mougel, L. Chatelain, J. Hermle, R. Caciuffo, E. Colineau, F. Tuna, N. Magnani, d. A. Geyer, J. Pécaut and M. Mazzanti, Angew. Chem., Int. Ed., 2014, 53, 819; (c) S. Wang, J.-L. Zuo, S. Gao, Y. Song, H.-C. Zhou, Y.-Z. Zhang and X.-Z. You, J. Am. Chem. Soc., 2004, 126, 8900; (d) J. S. Miller, Chem. Soc. Rev., 2011, 40, 3266.

37 J. A. Mydosh, Spin glasses: an experimental introduction, Taylor \& Francis, London, Washington, DC, 1993.

38 X.-M. Zhang, K. Wang, Y.-Q. Wang and E.-Q. Gao, Dalton Trans., 2011, 40, 12742.

39 Y.-L. Wu, F.-S. Guo, G.-P. Yang, L. Wang, J.-C. Jin, X. Zhou, W.-Y. Zhang and Y.-Y. Wang, Inorg. Chem., 2016, 55, 6592.
40 M. Chen, H. Zhao, E. C. Sañudo, C.-S. Liu and M. Du, Inorg. Chem., 2016, 55, 3715.

41 Y.-Q. Wang, X.-M. Zhang, X.-B. Li, B.-W. Wang and E.-Q. Gao, Inorg. Chem., 2011, 50, 6314.

42 S. Wöhlert, J. Boeckmann, M. Wriedt and C. Näther, Angew. Chem., Int. Ed., 2011, 50, 6920.

43 Z.-X. Wang, T.-W. Wang, Y.-Z. Li, S. Ohkoshi, K. Hashimoto, Y. Song and X.-Z. You, Inorg. Chem., 2007, 46, 10990.

44 X.-J. Li, X.-Y. Wang, S. Gao and R. Cao, Inorg. Chem., 2006, 45, 1508.

45 (a) C. Coulon, H. Miyasaka and R. Clérac, in Single-Molecule Magnets and Related Phenomena, ed. R. Winpenny, Springer Berlin Heidelberg, Berlin, Heidelberg, 2006, p. 163; (b) H. Miyasaka, M. Julve, M. Yamashita and R. Clérac, Inorg. Chem., 2009, 48, 3420.

46 J. M. Loveluck, S. W. Lovesey and S. Aubry, J. Phys. C: Solid State Phys., 1975, 8, 3841.

47 R.-M. Wei, F. Cao, J. Li, L. Yang, Y. Han, X.-L. Zhang, Z. Zhang, X.-Y. Wang and Y. Song, Sci. Rep., 2016, 6, 24372.

48 M. Rams, E. V. Peresypkina, V. S. Mironov, W. Wernsdorfer and K. E. Vostrikova, Inorg. Chem., 2014, 53, 10291.

49 L. Bogani, A. Caneschi, M. Fedi, D. Gatteschi, M. Massi, M. A. Novak, M. G. Pini, A. Rettori, R. Sessoli and A. Vindigni, Phys. Rev. Lett., 2004, 92, 207204. 